\title{
STUDI ANGKAT ANGKUT KARUNG BERAS BAGI PEKERJA DI PENGGILINGAN PADI
}

\author{
Girindra Yoga Pratama*)1); Djamaluddin Ramlan \\ 1)Jurusan Kesehatan Lingkungan; Poltekkes Kemenkes Semarang \\ Jl. Raya Baturraden KM 12; Purwokerto; Jawa Tengah; Indonesia
}

\begin{abstract}
Abstrak
Angkat-angkut adalah suatu aktivitas yang sering kita lihat di penggilingan padi. Aktivitas tersebut membutuhkan tenaga cukup besar dan mempunyai resiko yang besar pula sehingga aktivitas tersebut tidak memperhitungkan posisi kerja dan berat yang diangkat. Pada umumnya resiko sering dialami oleh pekerja angkat-angkut yang sering dialami oleh pekerja angkat-angkut adalah cedera tulang belakang yang diakibatkan oleh adanya sikap kerja yang tidak alamiah dimana pada salah satu bahu atau letakan dipunggung. Akibatnya posisi tubuh dalam keadaan membungkuk yang menyebabkan terjadinya sikap kerja paksa dan gangguan muskulosketal. Untuk mengetahui cara mengangkat atau mengangkut karung bagi pekerja angkat-angkut dengan benar agar tidak terjadi keluhan pada kesehatan. Pemilitian ini menggunakan metode kualitatif bersifat deskriptif dengan pendekatan verivikatif. Hasil penelitian mewujudkan sikap kerja monoton 3 orang, dinamis 2 orang, jenis keluhan kerja yaitu kelelahan tangan, kelelahan badan, lelah punggung, badan pegal-pegal, nyeri pinggang. Berdasarkan hasil penelitian, dapat disimpulkan sikap kerja pegawai masih salah dalam sikap angkat-angkut, dan menyebabkan kelelahan tangan, badan pegal-pegal, nyeri pinggang. Saran untuk UD. Makmur Maju adalah diberikan gambar cara angkat-angkut yang benar agar tidak terjadi kesalahan dalam sikap angkat-angkut.
\end{abstract}

Kata kunci: Karung Beras; Padi; Studi

Abstract

[Study Of Warehouse Rice Arrangement for Workers in Rice Milling of Rice Villas ] Cargo is an activity we often see in rice mills. Such activity requires considerable manpower and has a great risk so that the activity does not take into account the position of work and weight removed. In general, the risks often experienced by haulers often experienced by haulers are spinal injuries resulting from unnatural work attitudes on one shoulder or put on the back. As a result the body position in a state of bending that causes the attitude of forced labor and musculosketal disorders. To know how to lift or transport sacks for hauling workers properly in order to avoid complaints on health. This research uses descriptive qualitative method with verivative approach. The results of the work embodied the work attitude of 3 people monotonous, 2 people dynamic, the type of work complaints of hand fatigue, body fatigue, tired back, body aches, low back pain. Based on the results of the study, it can be concluded that the employee's attitude is still wrong in the attitude of lifting, and causing fatigue of hands, body aches, low back pain. Suggestions for UD. Makmur Maju is given a picture of the correct way of lifting to avoid errors in the attitude of lifting.

Keywords: sacks of rice; rice; studies

\section{Pendahuluan}

Masalah yang terjadi dipenggilingan padi

*) Correspondence author (Girindra Yoga Pratama)

E-mail: girindratama@gmail.com
UD.Makmur Maju adalah tentang cara angkat-angkut yang masih salah dan pekerja merasakan keluhan seperti kelelahan tangan, kelelahan badan, nyeri pinggang. Singga pegawai harus diberitau tentang cara 
angkat-angkut yang benar.

Angkat-angkut adalah suatu aktivitas yang sering kita lihat di penggilingan padi. Aktivitas tersebut membutuhkan tenaga yang cukup besar dan mempunyai resiko yang besar pula sehingga aktivitas tersebut tidak memperhitungkan posisi kerja dan berat yang di angkat. Bagi pekerja yang terpenting adalah bagaimana mereka bisa bekerja dengan cepat dan memperoleh output yang banyak.

Tanpa di sadari aktivitas angkat-angkut yang di lakukan pekerja dapat menyebabkan penyakit ataupun cedera tulang belakang terlebih jika pekerjaan tidak di lakukan dengan benar.) Jika kalau resiko tuntutan lebih besar dari kemampuan seseorang maka akan terjadi penampilan akhir yang bisa di mulai oleh adanya ketikdak nyamanan, overstrees, kelalahan, kecelakaan, cedera, rasa sakit dan tidak produktif. (Anis, 2007)

Pada umumnya resiko yang sering di alami oleh pekerja angkat-angkut adalah cedera tulang belakang yang diakibatkan oleh adanya sikap kerja yang tidak alamiah dimana pada salah satu bahu atau di letekan di punggung. Selain itu beban yang di angkut terlalu berat dan pembebanan tidak merata. Akibatnya posisi tubuh dalam keadaan membungkuk yang menyebabkan terjadinya sikap kerja paksa dan gangguan muskuloskeletal( Listiarini, 2016)

Pekerja angkat-angkut pembebanan lebih terletak pada otot terutama pada punggung, cekungan mengarah ke belakang (loradosa pinggang) dan pada daerah dada, cekungan mengarah ke depan (kifosa dada) (Winnar, 2001 dan Listiarini, 2016)

Demikian pula yang terjadi di penggilingan padi di Desa Rempoah Kecamatan Baturraden Kabupaten Banyumas, semua aktivitas angkat-angkut masih di lakukan dengan tenaga manusia baik laki-laki maupun perempuan. Berat beban yang diangkat juga tidak pernah di perhatiakan terlebih pada pengangkutan kepala yang di lakukan oleh pekerja laki-laki. Berat beban yang diangkut oleh pekerja wanita tersebut adalah $\pm 60 \mathrm{~kg}$. Beban tersebut melebihi batasan angkat yang di anjurkan. Batas angkat beban seberat $10 \mathrm{~kg}$ dianjurkan untuk jarak pendek, beban sebesar $15-18 \mathrm{~kg}$ dianjurkan untuk pekerja mengangkut yang terus-menerus, dan beban sebesar $40 \mathrm{~kg}$ untuk mengakat sekali-kali (suma'mur 1985 \& Anis, 2016).

Komisi Kesehatan dan Keselamatan Kerja merekomendasikan batasan angkat lebih dari 55kg harus dilaksanakan dengan menggunakan peralatan mekanis dan harus dibawah pengawasan ketat (Nurmianto, 1998 \& Anis, 2016). Akan tetapi pada pekerjaan angkat-angkut di penggilingan padi di Desa Rempoah Kecamatan Baturraden Kabupaten Banyumas dilakukan secara manual tanpa menggunakan peralatan mekanis maupun alat bantu

Keluhan yang dirasakan pekerja adalah Apabila seseorang dalam bekerja mengangkat atau menurunkan, dan membawa barang dilakukan secara langsung tanpa bantuan alat apapun dapat terjadi kecelakaan kepada pekerja seperti nyeri pinggang, kelelahan, badan pegal-pegal. Low back Pain (LBP) atau nyeri pinggang merupakan rasa nyeri yang terjadi didaerah punggung bagian bawah dan dapat menjalar ke kaki terutama ke belakang dan samping luar. Keluhan utama nyeri pinggang akibat sikap kerja yang salah dapat berupa pegal di pinggang yang bertahun-tahun, pinggang terasa kaku, sulit di gerakan, dan terus menerus lelah (Khushardianto, 2010)

Alasan pengambilan judul karena proses angkat angkut karung beras bagi pekerja di penggilingan padi Desa Rempoah Kecamatan Baturraden Kabupaten banyumas masih salah dalam mengangkat-angkut karung beras yang dapat menyebabkan cedera.

Hasil penelitian pegawai merasakan nyeri pada punggung, kelelahan,pinggul terasa kaku, sakit pada pinggul dan jika tidak di beri tau cara angkat-angkut yang benar bisa berakibat fatal.

\section{Metode}

Penelitian ini menggunakan metode kualitafif bersifat deskriptif dengan pendekatan verivikatif.

Lokasi penelitian ini di lakukan di tempat penggilingan padi di Desa Rempoah Kecamatan Baturraden Kabupaten Banyumas.

Input dalam penelitian ini adalah produktivitas kerja. Proses dalam penelitian ini adalah pakai sepatu yang tidak licin, pastikan kaki keadaan tegak dan sejajar dalam keadaan $90^{\circ}$ dan rapatkan kaki pada barang yang diangkat, bengkokkan lutut dan rapatkan kaki, pastikan pinggang tegak, angkat barang pada abdomen dan angkat barang perlahan-lahan, jika barang agak berat tumpu dengan otot kaki, pastikan lutut bengkok ketika mengangkat barang, dapatkan bantuan jika barang terlalu berat untuk seseorang, dan gunakan troli atau peralatan lain untuk mengalihkan barang yang terlalu berat. (Sumamur, 1989). Output dalam 
oenelitian ini adalah kelelahan tangan, kelelahan badan, lelah punggung, dan nyeri pinggang.

Subyek dalam penelitian ini adalah sikap kerja, cara angkat-angkut, beban kerja, jenis beban, keluhan pegawai, frekuensi angkat, jalur evakuasi, dan hasil pekerja menurut instrumen.

Pengumpulan data dengan cara pengamatan dan wawancara, lalu data hasil penelitian di tambahi dan diambi secara total.

\section{Hasil dan Pembahasan}

Gambaran lokasi UD.Makmur Maju merupakan salah satu penggilingan padi di Desa Rempoah Kecamatan Baturraden Kabupaten Banyumas. Didirikan pada tahun 1997 oleh bapak Subianto bersama bapak Slamet Agus.

UD.Makmur Maju memiliki luas tanah \pm $2200 \mathrm{~m}^{2}$ dan luas bangunan $215 \mathrm{~m}^{2}$ yang terdiri dari fasilitas bangunan yaitu ruang, ruang produksi, ruang penyimpanan beras, ruang produksi, WC, dan tempat parkir.

UD.Makmur Maju didirikan untuk penggilingan padi guna memenuhi kebutuhan masyarakat di wilayah Baturraden yang semakin meningkat dengan mengupayakan kualitas penggilingan yang sangat baik.

UD. Makmur Maju untuk menjaga profesionalitas pekerja yang bebas keluar masuk kerja, melakukan pemberian pelatihan kerja kepada setiap ada tenaga kerja baru agar dapat bekerja dengan baik sesuai prosedur kerja. Fasilitas juga yang diberikan perusahaan untuk inventaris transportasi kepada pekerja tertentu kendaraan sepeda motor dan sepeda ontel. Jumlah tenaga kerja ada 5 orang karyawan tetap. 1. Jumlah tenaga kerja berdasarkan sikap kerja

\begin{tabular}{cccc}
\multicolumn{4}{c}{ Tabel 1. Sikap kerja } \\
\cline { 3 - 4 } No & Responden & $\begin{array}{c}\text { Monoton } \\
\text { (orang) }\end{array}$ & $\begin{array}{c}\text { Dinamis } \\
\text { (orang) }\end{array}$ \\
\hline 1. & $\mathrm{~A}$ & 1 & 1 \\
2. & $\mathrm{~B}$ & 1 & - \\
3. & $\mathrm{C}$ & - & 1 \\
4. & $\mathrm{D}$ & 1 & 1 \\
5. & $\mathrm{E}$ & - & 1 \\
\hline & Jumlah & 3 & 4 \\
\hline
\end{tabular}

\section{Sikap Kerja}

Sikap kerja monoton adalah sesuatu yang sifatnya sama dengan sebelumnya, itu-itu saja, atau tidak ada variasinya. Seperti pada pekerja UD. Makmur Maju responden A, B, D.

Sikap kerja dinamis adalah sesuatu hal yang terus berubah sikap kerjanya dan berkembang secara aktif, atau seseorang yang hidupnya sangat antusias dengan banyak energy dan tekad yang tinggi yang seperti pekerja yang ada di penggilingan padi UD. Makmur Maju yang pekerja responden $\mathrm{C}$ dan $\mathrm{E}$ memiliki sikap kerja yang dinamis.

Di UD. Makmur Maju sikap kerja pegawai monoton berjumlah 3 orang dan sikap kerja dinamis ada 2 orang pekerja. Pekerja di UD. Makmur Maju melakukan sikap kerja yang baik tetapi ada 1 pegawai yang salah dalam melakukan sikap kerja sehingga pegawai melangami kelelahaan tangan, kelelahan badan, badan pegal-pegal, nyeri pinggang.

Saran untuk UD. Makmur maju sebaiknya pegawai yang salah dalam sikap angkat-angkutnya di beritahu agar tidak salah dalam proses angkat-angkut agar tidak mengeluh kelelahan tangan, nyeri pinggang, badan pegal-pegal.

Kesimpulan yang saya dapat dari UD.Makmur maju adalah dari 4 pekerja di UD.Makmur Maju masih terdapt pegawai yang masih salah dalam sikap angkat-angkut dan menyebabkan pegawai mengalamai kelelahan tangan, badan pegal-pegal, nyeri pinggang.

Cara angkut beban yang benar :

1) Posisi punggung dalam keadaan lurus

2) Ketika membawa atau menjinjing beban posisi tulang belakang harus tegak

3) Posisi tulang menerima beban yang besar atau sering mengangkat beban berat, maka sendi-sendi pada tulang belakang akan menekat tulang rawan dan berakibat merusak sendi dan jika dipaksa akan berakibat pembengkaan atau salah urat.

Cara angkut beban pekerja yang 4 sudah benar karena sudah mengetahui cara angkut beban yang benar, tetapi 1 pekerja masih salah dalam pengangkatan beban sehingga mengalami pembekaan atau salah urat dan kelelahan tangan, badan, nyeri pinggang.

\section{Jumlah responden berdasarkan beban kerja}

Tabel 2. Jumlah responden berdasarkan beban angkut

\begin{tabular}{lccccccc}
\hline \multirow{2}{*}{ No } & \multirow{2}{*}{$\begin{array}{l}\text { Responde } \\
\text { n }\end{array}$} & \multicolumn{4}{c}{ Frekuensi Beban angkat - angkut } \\
\cline { 3 - 8 } & & \multicolumn{3}{c}{ Gabah $(\mathrm{Kg})$} & \multicolumn{4}{c}{ Beras (Kg) } \\
\hline 1.20 & A & 1 & 1 & $30-40$ & $10-20$ & $20-30$ & $30-40$ \\
\hline 2. & $\mathrm{~B}$ & & 1 & 1 & 1 & 1 & 1 \\
3. & $\mathrm{C}$ & 1 & 1 & 1 & 1 & 1 & 1 \\
4. & $\mathrm{D}$ & 1 & 1 & 1 & 1 & 1 & 1 \\
5. & $\mathrm{E}$ & 1 & 1 & 1 & 1 & 1 & 1 \\
\hline & Jumlah & 4 & 5 & 5 & 4 & 5 & 5 \\
\hline
\end{tabular}

Beban kerja 
Kondisi beban kerja dilapangan yang diterima pegawai yang bekerja di penggilingan padi setiap harinya yaitu beban fisik saat melakukan pengangkatan sejumlah $40 \mathrm{~kg}$ setiap harinya dan dalam sehari pegawai harus melakukan pengangkatan beban sebesar $40 \mathrm{~kg}$ atau dalam seminggu brati harus melakukan pengangkatan sebanyak 6kali.

Saran pekerja yang berumur 40-50 tahun di bedakan beban angkatan karena umur yang sudah tidak produktif untuk mengangkat beban sebesar $40 \mathrm{~kg}$.

a. Jenis beban

Jenis beban terbagi menjadi 5 jenis :

1) Beban mati adalah segela sesuatu bagian struktur yang bersifat tetap, termasuk dalam hal ini berat sendiri tersetruktur

2) Beban hidup adalah semua beban yang bersifat sementara yang di tempatkan pada suatu tempat tertentu. Sebagai contoh adalah beban kendaraan pada area palkir, kelengkapan meja atau kursi pada kantor, dinding partisi, manusia, beban air pada kolam renang, beban air pada tangki air, dan lain sebagainya.

3) Beban gempa gempa adalah beban bekerja pada suatu struktur akibat dari pergerakan tanah yang disebabkan karena adanya gempa bumi ( baik itu gempa tektonik atau vulkanik ) yang mempengaruhi struktur tersebut. Gempa mengakibatkan beban pada struktur karena interaksi tanah dengan struktur karakteristik respon struktur. Beban gempa adalah beban percepatan tanah yang berupa rekemanan percepatan tanah untuk suatu gempa tertentu, sehingga untuk setiap waktu tertentu akan mempunyai harga percepatan tertentu.

4) Beban angina adalah beban yang bekerja pada suatu struktur akibat faktor yang mem-blok aliran angina, sehingga energy kinetic angina akan dikonversi menjadi tekanan energi potensial, yang menyebabkan terjadinya beban angina. Efek beban angina pada suatu struktur bergantung pada jenis kecepatan udara, sudut luas angina, bentuk dan kekakuan struktur, faktor-faktor yang lain.

5) Lainyya adalah beberapa tempat di beberapa Negara terdapat beban salju di perhitungkan dalam diseain atap bangunan, selain itu terdapat pula beban air hujan. Pada umumnya beban air ujan juga di perhitungkan dalam atap bangunan, pada perencanaan bangunan dinding penahan tanah ( retaining wall ). Selain beban-beban yang telah di definisikan, terdapat beberapa jenis beban yang lain, yaitu beban kejut (impact), beban api, beban akibat perubahan temperature dan lain sebagainya Pada pekerja angkat-angkut di penggilingan padi

UD. Makmur Maju jenis beban berupa karung goni dan berisi padi dan memiliki berat $40 \mathrm{~kg}$.

2. Jumlah tenaga kerja yang mempunyai keluhan

Tabel 3. jumlah tenaga kerja yang mempunyai keluhan saat

\begin{tabular}{ccccccc}
\multicolumn{7}{c}{ angkat-angkut } \\
\cline { 2 - 7 } No & \multicolumn{5}{c}{ Keluhan } \\
$n$
\end{tabular}

Pegawai yang bekerja di penggilingan padi terdiri dari 5 orang pekerja. Selama observasi di temukan 1 orang pegawai yang mempunyai keluhan seperti nyeri pinggang, badan pegal-pegal, hal tersebut diakibatkan dari sikap angkat-angkut yang salah. Sedangkan untuk 4 orang pegawai tidak mengalami keluhan apapun dikarenakan sudah menerapkan sikap angkat-angkut yang benar.

\section{Jalur yang dilalui}

Kondisi jalur yang dilalui oleh pekerja tidak naik turun tetapi lantai licin dikarenakan ada genangan air dari saluran perpipaan air sehingga menyebabkan air menggenangi jalur yang digunakan oleh pegawai untuk bekerja. Dengan melihat kondisi tersebut resiko kecelakaan kerja yang terjadi adalah pegawai dapat terpeleset dan hal tersebut dapat menyebabkan adanya kecelakaan kerja

3. Frekuensi angkat-angkut beban bagi pekerja 4.

Tabel 4. Jumlah frekuensi angkat-angkut beban

\begin{tabular}{|c|c|c|c|c|c|}
\hline \multirow{2}{*}{ No } & \multirow{2}{*}{ Responden } & \multicolumn{4}{|c|}{ Frekuensi angkat - angkut / hari } \\
\hline & & 1 kali & 2 kali & 3 kali & 4 kali \\
\hline 1. & $\mathrm{~A}$ & 1 & 1 & 1 & \\
\hline 2. & B & 1 & 1 & 1 & \\
\hline 3. & $\mathrm{C}$ & 1 & 1 & & 1 \\
\hline 4. & D & 1 & & 1 & 1 \\
\hline 5. & E & 1 & & 1 & 1 \\
\hline \multicolumn{2}{|c|}{ Jumlah } & 5 & 3 & 4 & 3 \\
\hline
\end{tabular}

Berdasarkan dari table di atas semua pegawai mengangkat beban sebesar $40 \mathrm{~kg}$ setiap 
harinya dan yang mengalami masalah dalam mengangkat beban adalah Responden E karena sikap angkat-angkut salah sehingga mengalami nyeri pinggang, mudah lelah, badan pegal-pegal

Tabel 5. Pengangkatan beban dan frekuensi

\begin{tabular}{lcrrrr}
\hline \multirow{2}{*}{ No } & \multirow{2}{*}{$\begin{array}{c}\text { Respond } \\
\text { en }\end{array}$} & \multicolumn{5}{c}{\begin{tabular}{c} 
Frekuensi Beban Angkat \\
\cline { 3 - 6 }
\end{tabular}} & & $\mathrm{kg}$ & $\begin{array}{c}20-30 \\
\mathrm{~kg}\end{array}$ & $30-40 \mathrm{~kg}$ & \\
\hline 1. & $\mathrm{~A}$ & 4 & 5 & 5 & \\
2. & $\mathrm{~B}$ & 4 & 5 & 5 & \\
3. & $\mathrm{C}$ & 4 & 5 & 5 & \\
4. & $\mathrm{D}$ & 4 & 5 & 5 & \\
5. & $\mathrm{E}$ & 4 & 5 & penggilingan & padi
\end{tabular}

UD.Makmur Maju ada 5 pekerja tetap setiap hari pekerja melakukan pengangkatan lebih dari 1 kali bahkan ada sampai yang 3 kali pengangkatan beban.

\section{Pengendalian permasalahan angkat-angkut}

Memberitahukan kepada pekerja yang salah tentang cara angkat-angkut yang benar dan memberi gambar contoh angkat-angkut yang benar sehingga pekerja yang salah dalam sikap angkat-angkut tidak mengalami nyeri pinggang dan encok serta pegal-pegal setiap harinya. Cara angkat angkut yang benar :

a. Pakai sepatu yang stabil, bukanya sepatu yang bertumit tinggi, sendal .

b. Pastikan kaki dalam keadaan teguh dan stabil, dalam keadaan 90 dan rapatkan kaki pada barang yang akan diangkat.

c. Bengkokkan lutut dan rendahkaan badan.

d. Pastikan pinggang tegak.

e. Angkat barang pada abdomen dan angkat barang perlahan-lahan, jika barang agak berat tumpu dengan otot kaki.

f. Pastikan lutut bengkok ketika mengangkat barang.

g. Dapatkan bantuan jika barang terlalu berat untuk seseorang.

h. Gunakan troli atau peralatan lain untuk mengalihkan barang yang terlalu berat.(Suma"mur, 1989).

6. Pembahasan pengangkatan beban

Dipenggilingan padi UD. Makmur Maju setiap hari melakukan penggilingan padi dengan berat $10-20 \mathrm{~kg}, 20-30 \mathrm{~kg}$. $30-40 \mathrm{~kg}$, tetapi rata rata berat beban yang diangkat adalah sebesar $40 \mathrm{~kg}$ setiap harinya oleh pegawai di penggilingan UD. Makmur Maju.

\section{Simpulan dan Saran}

Simpulan dari hasil yang diperoleh adalah:

a. Beban berat angkat-angkut pekerja sebesar $40 \mathrm{~kg}$.

b. 4 responden bekerja dengan sikap kerja benar dan 1 responden bekerja dengan sikap kerja yang salah.

c. Keluhan yang di alami pekerja angkat-angkut adalah kelelahan tangan, badan pegal-pegal, nyeri pinggang.

d. Pencegahan yang harus di lakukan adalah memberitau kepada responden yang salah tentang cara angkat-angkut agar tidak mengalami keluhan.

Disarankan ditempat kerja perlu diberi gambar cara angkat-angkut yang benar.

\section{Ucapan Terima Kasih}

Terima kasih disampaikan kepada Poltekkes Kemenkes Semarang yang telah mendanai keberlangsungan jurnal ini.

\section{Daftar Pustaka}

Alfred Sutrisno Sp. BS. 2002. Mencegah Nyeri Punggung. eramusalim.com./artikel/index.

Anis, M., Alghofari, A. K., \& Muslikhatun, H. (2007). ANALISIS PENGARUH PENGGUNAAN" STAGEN" PADA AKTIVITAS ANGKAT-ANGKUT DI PASAR LEGI SURAKARTA. Jurnal Ilmiah Teknik Industri, 6(1), 9-17.

Badudu, Zein. 1994, Kamus Besar Bahasa Indonesia, Jakarta: PT. Bina Rupa Aksara.

Doewas, M. 1996. Penuaan dan kapasitas Kerja. Jakarta: Penerbit Buku Kedokteran EGC.

Kushardianto W. Pengaruh Teknik Mengangkat Beban Terhadap Nyeri Pinggang pada Buruh Tani di Dukuh Plumbon, Desa Sentono, Kecamatan Karangdowo, Kabupaten Klaten Tahun 2010 [Skripsi]. Surakarta: Universitas Sebelas Maret; 2010.

Listiarini, A., Widjasena, B., \& Wahyuni, I. (2016). Hubungan Kekuatan Otot Punggung Dengan Keluhan Nyeri Punggung Pada Porter Di Stasiun Tawang Semarang. Jurnal Kesehatan Masyarakat (e-Journal), 4(4), 636-644. 